\title{
The Role of Information Technology in the Development of Society and Economy
}

\author{
Jiyu Peng
}

\author{
School of Marxism, Beijing Jiaotong University, Beijing, 100044, China \\ ${ }^{*}$ Corresponding author Email: pjy18811500192@sina.com
}

\begin{abstract}
As one of the most important inventions in the 20th century, information technology has the characteristics of permeability, transmission, sharing, risk and interaction. It has an important influence on the development of human society and economy. Among them, the main impact is to promote scientific and economic management, to promote the development of productivity, and to upgrade the economic structure. In order to make good use of the information technology in social economy, it is necessary to understand the role of information technology, to adhere to the peopleoriented value orientation, to attach importance to and cultivate information technology talents, to strengthen the investment and management of information technology funds, and to pay attention to the basic research and transformation of information technology.
\end{abstract}

Keywords: information technology, social economy, role.

\section{THE UNDERSTANDING OF INFORMATION TECHNOLOGY}

China has made a breakthrough in the fields of communication technology, high-performance computer technology and optoelectronic technology, which provides a foundation for the development and construction of information technology in China.

\subsection{The Concept of information technology}

People have different understanding of information technology from different perspectives. In a broad sense, it includes the production and application of information technology. Among them, the technological production of it is reflected in the fields of microelectronics production, computer hardware and software and telecommunication equipment, while the application of it is mainly reflected in the fields of information service and information management. This concept emphasizes the production and practical application of information technology. In a narrow sense, information technology only refers to the use of computers or communication equipment and other "hardware" or "software" to capture, store, process, transmit and apply all kinds of information.

\subsection{The Concept of information technology}

Information technology has formed its unique characteristics, including permeability, transmission, risk and interactivity.
Permeability. The penetration of information technology means that information technology can enter many other industries and fields without barriers. Because information technology itself has the independent dynamic process of diffusion and technology discovery, together with the atmosphere of information technology innovation and the basis of knowledge accumulation, it has formed a constantly changing technology system and technology group. These technologies are not only applied in the industry, but also widely introduced into the economic, political, cultural and other fields, providing support for the various fields. [1]

Transitivity. The transitivity of information technology means the use of information technology to achieve the transmission of information in time and space. From the perspective of time, people transfer information through various communication technologies, such as using the storage and recording functions of information technology to realize the information transfer activities from "present" to "future", or from "past" to "present". From the perspective of space, people use information technology to transfer knowledge from one place to another, from one country to another, and realize the transmission of information beyond space.

Risk. The risk of information technology mainly refers to the social risk in the process of dissemination and application. For one thing, the way of information dissemination through information technology is nonlinear. In today's complex social environment, some people report information partially or spread false 
information out of consideration of economic, political and cultural factors. It is not only easy to cause information distortion and make it difficult for people to understand things objectively, but also may aggravate contradictions among people and cause major social conflicts. There will be risks. For another, there are many uncertainties and risks in the development and application of information technology. Information technology is in the forefront of the development of contemporary science and technology, with a high degree of advance and guidance. Whether from the market demand or from the perspective of technology development, information technology has uncertainty and risk.

Interactivity. The interactivity of information technology means that information technology can provide people with rich man-machine interface, which is excellent in both pictures and literary compositions. It can also provide people with connection mode which is in line with the characteristics of people's associative thinking and associative memory. Moreover, it can provide immediate feedback and facilitate selfregulation. This kind of interaction is reflected in the communication and feedback between people.

\section{THE IMPACT OF INFORMATION TECHNOLOGY ON THE DEVELOPMENT OF SOCIETY AND ECONOMY}

It is necessary to apply information technology to people's life, enterprise production and management. Information technology has produced a series of important effects on social and economic development.

\subsection{To promote scientific and economic management}

In the economic field, information technology is widely used in enterprise management, information collection and business decision-making. People apply the Internet technology to the data processing of enterprise management. Internet technology can accurately record the relevant data. Authentic data can not only minimize the mistakes of enterprise work, improve the reliability of enterprise operation, provide strong evidence for the scientific management of enterprises, but also effectively reduce the interest damage caused by inaccurate data. In addition, the database established by people using information technology is becoming more and more important for economic management. According to the requirements of market economy, enterprises have set up various databases, including energy economy management database, agricultural management database and financial supervision database. These data are helpful for enterprises to analyze the law of economic operation, to promote the upgrading and transformation of industrial structure, and then to effectively realize the scientific economic management.

\subsection{To promote the development of productivity}

Human is the leading factor in productivity. The history of production development shows that mastering information technology is an important condition for workers to practice their production functions. In ancient times, people relied on their own experience and physical strength to complete production. In modern society, social production requires more and more people's knowledge. Generally speaking, the richer people's knowledge structure is, the more they can adapt to the requirements of socialized mass production and promote the development of social productive forces. People use the information technology to constantly learn the advanced production knowledge and skills of advanced countries, so that workers and both factors can be well integrated into the production process, which can maximize the production enthusiasm of workers, and then improve productivity.[2]

\subsection{To upgrade the economic structure}

On the one hand, the development of information technology will inevitably lead to the optimization and upgrading of industrial structure. Information technology makes the production of goods more efficient. Especially since the 1980s, while the old production department can not adapt to the requirements of the development of new technology, the new production department has gradually developed What follows is the continuous optimization and upgrading of the industrial structure. This is due to the transformation of traditional industrial technology by information technology, which improves the technical level of the industry, increases the added value of the industry, and improves the degree of industrial intensification and processing. On the other hand, information technology promotes the upgrading of investment structure. At present, China's investment structure is more and more focused on the field of information technology development and human resources. Among them, the proportion of investment in digital technology, electronic technology and computer technology is rising. Similarly, modern investment has gradually shifted from traditional "hard investment" in large-scale projects and infrastructure projects to "soft investment" in talents, information and services. Therefore, information industry is not only a capital intensive industry in China, but also an investment in this field. 


\subsection{To promote the development of economic globalization}

Information technology promotes the rapid development of economic globalization. Economic globalization makes the economic ties between countries more and more close, the domestic market and the international market tend to merge, and finally makes the economies of all countries in the world deeply integrate, so that the production and circulation in the world become an inseparable whole. [3] Practice has proved that the development of information technology is a strong support to promote economic globalization. The development of the Internet, e-mail, communication and other technologies has strengthened the links between countries in the world. The development of information technology not only enables isolated individuals to connect and exchange information independently, but also breaks the barriers of man-made and national boundaries and violently impacts the barriers of traditional ideas. Information technology allows all kinds of information to flow freely through time and space, greatly shortening the space-time distance between countries, and the earth has become a "global village". In particular, the development of communication network and transportation technology has greatly reduced the cost of economic and trade between countries, promoted the commodity exchange and flow between countries, promoted the economic exchanges between countries, and promoted the development of economic globalization.

\section{THE INNOVATIVE PATH OF INFORMATION TECHNOLOGY IN THE DEVELOPMENT OF SOCIETY AND ECONOMY}

In order to made good use of information technology in social economy, we need to further improve the following measures.

\subsection{To correctly understand the function of information technology}

In order to give full play to the role of information technology in economy and society, we must recognize the role of information technology in thought and action.

First, to innovative ideas. The correct idea guides people's correct action. People should understand information technology correctly. Only in this way can we effectively use information technology to create greater economic benefits, to avoid social risks, and to promote the steady and orderly development of economy and society.

Second, to establish a platform. The development of information technology must have a good platform, which mainly includes the planning of information technology application and the unified standard of information technology management. All of these create a good platform for the development of information technology, promote economic entities to use it to realize the effective allocation of resources, and promote the rational development of social economy.

\subsection{To adhere to the people-oriented value orientation}

The development of information technology must adhere to the people-oriented value orientation, the development and application of technology must be oriented to all mankind, not only to emphasize the sense of responsibility, but also to highlight the guidance of humanistic spirit. Only in this way can we create favorable conditions for social and economic development.

First, the sense of responsibility should be maintained in technological development. In our life, information technology often has uncertain consequences, even negative effects. When developing and applying modern information technology, we should consider the safety and happiness of the people, not only the interests of some individuals, but also the supervision of public opinion. Taking a responsible attitude towards the development of information technology is not only responsible for the present human beings, but also for the future human beings.

Second, technological development should be guided by humanistic spirit. The guidance of humanistic spirit is not to reject the development science and technology. On the contrary, we should know that science and technology is regarded as the first productive force, it needs the support of humanistic spirit. [4] Because humanistic spirit advocates sensibility and diversity, it provides people with a basic yardstick to understand and transform the world. To realize the guidance of humanistic spirit, we must improve our own scientific and cultural quality, and strengthen the study of theoretical knowledge.

\subsection{To respect information technology talents}

It is an important resource for the development of economy and society to attach importance to and cultivate information technology talents. The key to achieve good economic development is to firmly grasp talents. [5]

First, to broaden the channels for the introduction of scientific and technological talents. The government or relevant enterprise departments can regularly introduce scientific and technological talents to other cities 
through high salary to provide suitable talents for enterprise development. At the same time, we should attract scientific and technological talents in various ways, such as technology shares, talent leasing, achievement transfer and other effective ways, so as to attract scientific and technological talents and turn their talents into economic output.

Secondly, to give necessary policy guarantee. The government provides preferential fiscal and tax policies and government procurement system with clear guidance for enterprises to absorb scientific and technological talents, guides enterprises to absorb scientific and technological talents, and improves the policy system for enterprises to absorb scientific and technological talents.

Third, to optimize the school education environment. The government should provide basic teaching implementation for university members, and universities should have full autonomy in scientific research plans and projects, encourage university members to innovate constantly, do not blindly believe in authority, and create a relaxed academic atmosphere. At the same time, we should create a group innovation atmosphere among the scientific research personnel in the school. The innovation within the group will stimulate the interest and spirit of each member, so as to cultivate students' innovation ability in this atmosphere.

\subsection{To strengthen the investment and management of Information technology's funds}

The investment of funds has laid a material foundation for the rapid development of information technology. The financial support for information technology mainly comes from the government, enterprises and social organizations.

First, the government should not only formulate relevant information technology investment system, clarify the scope of investment, and improve the effectiveness of investment, but also increase efforts to invest in those science and technology projects that are of great significance to the development of the national economy. Especially for those science and technology projects that can greatly drive the development of the national economy and can not be operated by nongovernmental support, the government can even give full funding. For those science and technology projects that can rely on their own development, the government should play a leading role in guiding the smooth progress of science and technology projects funded by social forces.

Second, enterprises should strengthen the control of it capital investment. Enterprises follow the overall principle of obtaining the maximum economic benefits with the minimum investment in information technology. At the same time, the investment of enterprise information technology funds should be based on the development and take into account the current situation. The use of the fund should not only conform to the law of economic development, but also meet the needs of the enterprise's own development.

Third, social organizations should strengthen the supervision of the public sector on it investment. Social organizations have the characteristics of non-official and non-profit. Social organization has become the most important subject of social public power outside the government. In the face of the government's investment and use of information technology funds related to public interests, social organizations should strengthen their supervision, ensure that the relevant departments work together to invest and use funds, so as to provide effective social security for the development of information technology.

\subsection{To pay attention to the basic research and transformation of information technology}

To pay attention to the basic research and transformation of information technology, information technology can not promote the development of economy and society without basic research and transformation. Among them, for one thing, basic research is the premise of the development of information technology. Without basic research, it is difficult to develop information technology. For another, the innovation of technology can bring us a lot of benefits.

First, to pay attention to the basic research. The results of basic research contains new knowledge about, such as textbooks and academic papers. The cycle of basic research longer than other research cycle, which makes it difficult for researchers to obtain reasonable economic remuneration by virtue of these research. Therefore, for the basic research of information technology, the government should increase the scope of funding and reduce the declaration cost. At the same time, we should implement the right of independent use of scientific research funds, so that it can be used for the research.

Second, to pay attention to the transformation of information technology. Information technology must be transformed in order to be applied to social life. The transformation of information technology can be realized through the joint mode of enterprises and institutions. Among them, enterprises can use their own advantages to collect information conveniently and quickly, in order to effectively guarantee the transformation and utilization of information resources of scientific and technological achievements. Or the transformation of information technology can also be achieved through the establishment of information 
consulting center. In the process of transformation of scientific and technological achievements, a perfect information consulting center can not only expand the channels of scientific and technological achievements release, but also ensure that they are more reasonable.

\section{SUMMARY}

Information technology is a double-edged sword in social and economic development. It can bring both positive and negative effects to social economy. To give full play to its positive effect, we should correctly grasp the role of information technology, adhere to the value orientation of humanism, pay attention to the cultivation of information talents and strengthen capital investment. Only in this way can we use information technology to promote the rapid development of social economy.

\section{AUTHORS' CONTRIBUTIONS}

The research conception, design, writing, translation, modification and finalization of this article are all completed by myself.

\section{ACKNOWLEDGMENTS}

This paper is formed on the basis of drawing lessons from other scholars, and I would like to thank the authors one by one.At the same time, I also thank myself for my efforts and perseverance in writing this paper.

\section{REFERENCES}

[1] Still, Ni Bo. Analysis of the characteristics of modern information technology $[\mathrm{J}]$. Journal of Chinese Library Science, 1998 (05): 73-77.

[2] Tang Changli. The revolution of productive forces in the 21 st century -- on the third industrial revolution [J]. Journal of theory, 2015 (10): 40-45.

[3] Peng Sida. Information technology revolution and economic globalization [J]. Journal of Hubei University (PHILOSOPHY AND SOCIAL SCIENCES), 2002 (04): 23-26.

[4] Liu Hailong. The humanistic meaning of Marx's view of science and technology [J]. Socialism research, 2011 (03): 1-5.

[5] Zhao Yannian. Thoughts on the transformation of economic development mode and the construction of scientific and technological talent team [J]. Chinese talent, 2012 (08): 46-47. 